\title{
Geociências
}

\section{Reintegração dos finos provenientes do beneficiamento de argila no processo de produção de revestimentos via seca}

\author{
Carolina Del Roveri \\ Geóloga-UNESP (Processos FAPESP 02/00858-0 e 05/03683-5) \\ Av. 24A, 1515 - Rio Claro - São Paulo - Brasil - CEP 13506-900 \\ E-mail:cdroveri@rc.unesp.br \\ Antenor Zanardo \\ Geólogo, Dr., Livre Docente - DPM/UNESP \\ Av. 24A, 1515 - Rio Claro - São Paulo - Brasil - CEP 13506-900 \\ E-mail: azanardo@rc.unesp.br \\ José Francisco Marciano Motta \\ Geólogo, Dr. - Pesquisador - IPT S.A. \\ Av. Prof. Almeida Prado, 532 - Cid.Universitária - São Paulo - CEP 05508-901 \\ E-mail:jfmotta@ipt.br
}

\section{Resumo}

Na região de Rio Claro (SP), localiza-se o Pólo Cerâmico de Santa Gertrudes, responsável por cerca de 50\% da produção nacional de revestimentos. Durante o beneficiamento da argila e preparação da massa, cerca de 2 a $3 \%$ argila fina é colocada em suspensão no ar, sendo quase toda retida nos filtros de manga. Esse material fino, por problemas de homogeneização ou tecnológico, representa perda de material e se constitui em um potencial agente de contaminação do ar e da água, necessitando ser armazenado. A presente pesquisa buscou viabilizar o aproveitamento do pó retido nos filtros, no próprio processo, através da granulação da massa por aspersão de barbotina preparada com o pó. Investigaram-se a composição ideal da barbotina e a influência dessa metodologia no produto final, comparando a massa granulada por aspersão com a massa-padrão.

Palavras-chave: Revestimentos, via seca, finos, matériaprima, beneficiamento.

\begin{abstract}
In the region of the Rio Claro (SP) is located the Santa Gertrude's Ceramic Pole, responsible for around $50 \%$ of the national ceramic tile manufactured. During the clay's ore treatment and powder preparation, 2 to 3 percent of the fine clay is lost in the air, in suspension. Almost all the material is restrained in bag filters. Currently, because of blending problems, this fine material represents a loss of material, which could become a potential agent for air and water contamination, and this material needs to be stored. This research examined the possible use for the filterbag dust while in process, through granulation of the material by aspersion of the barbotine prepared with a powder. We investigated the ideal composition of the suspension and the influence of this method in the end product, comparing the granulated mass by aspersion with the standard mass.
\end{abstract}

Keywords: Ceramic tiles, dry milling, fine particles, raw material, improvement. 
Reintegração dos finos provenientes do beneficiamento de argila no processo de produção de...

\section{Introdução}

O tema da presente pesquisa relaciona-se a um importante problema, apresentado pela região ceramista, inerente à preparação da matéria-prima pelo processo de via seca, onde são geradas toneladas de material fino, coletado nos filtros de manga (Roveri \& Zanardo, 2003). O Pólo Cerâmico de Santa Gertrudes é responsável pela produção de cerca de $50 \%$ do revestimento cerâmico consumido no Brasil e, em quase sua totalidade, utiliza o processo de via seca por moinhos de martelo e pendular (Masson, 2001), sensivelmente menos oneroso que outros processos de preparação da massa, tornando o custo do processamento cerâmico menor, resultando em produtos com alto poder de venda, a preços baixos (CCB, 2005). Na preparação da massa pelo processo de via seca, uma parte da matéria-prima, de granulometria mais fina (cerca de 2 a $3 \%$ ), é colocada em suspensão e prontamente retida por filtros de manga, tornando o ambiente das usinas ou fábricas bem menos insalubres. Dessa forma a fração retida, além de representar desperdício de matéria-prima, causa gastos com acondicionamento e armazenamento apropriado ou causa problemas ambientais, quando descartada sem tratamento conveniente, uma vez que é facilmente colocada em suspensão pelo ar ou levada pelas águas das chuvas, poluindo corpos d'água dentro da área de influência do empreendimento (Roveri \& Zanardo, 2003).

Nassetti (1996) verificou que, na maioria das vezes, os resíduos adicionados às massas modificam as características das peças cerâmicas, positiva ou negativamente, dependendo de sua afinidade físico-química com a matéria-prima base.

Com base no exposto, o objetivo desse trabalho é caracterizar massas-padrão e massas com adição da fração fina, por aspersão de barbotina, buscando a reutilização desse resíduo, onde se almeja contribuir com a minimização do impacto ambiental causado pelo parque cerâmico da região, garantir um aprovei- tamento mais racional da matéria-prima e desenvolver metodologia e tecnologia, visando a um aumento da qualidade do produto em paralelo com a diminuição dos custos de produção, tornando os produtos mais competitivos.

\section{Materiais e métodos}

Foram utilizados, como materiais de estudo, uma massa cerâmica, para fabricação de pisos, e revestimentos, de uma empresa do Pólo Cerâmico de Santa Gertrudes e a fração fina retida nos filtros de manga da mesma empresa. Os materiais foram analisados no Labcer/IGCE/ UNESP por fluorescência e difração de raios $\mathrm{X}$ (equipamento de fluorescência de raios $\mathrm{X}$ marca Phillips, modelo PW 2510 e difratômetro de raios X marca Siemens D5000, medidas com radiação

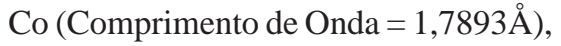
passo de 0,05 graus e tempo de exposição de 0,8 s por cada passo. Através de sedígrafo (raios X) de marca Siemens SF 500, obteve-se a distribuição granulomé-

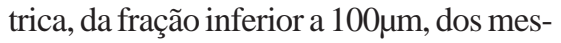
mos. Realizou-se a caracterização reológica dos finos, quanto à determinação de $\mathrm{pH}$, curva de defloculação e concentração crítica de sólidos, a fim de dimensionar o quanto desse material poderia ser adicionado à massa-padrão. Os ensaios foram realizados em viscosímetro rotacional Brookfield, modelo RTV, e agitador automático Siemens. A curva de defloculação consiste na determinação da quantidade ótima de defloculante para que seja obtida a mínima viscosidade. Partiu-se de uma massa moída a seco sem defloculante, que, após a adição de água, foi agitada por dois minutos em agitador mecânico, para, então, ser realizada a primeira leitura. Foram realizadas adições sucessivas de silicato de sódio, atuando como defloculante, e, durante essa operação, para cada adição realizava-se o período de agitação e se fazia a leitura no reômetro. Para o ensaio de concentração crítica de sólidos, realizou-se o mesmo tipo de moagem e foram feitos os mesmos procedimentos de agitação da suspensão. Utilizando como base a quantidade ótima de defloculante determina- da no ensaio anterior, partiu-se de uma concentração de sólidos de $65 \%$ em peso (concentração mínima para que o processo industrial seja econômico). Foram realizadas diluições, para diminuir a concentração de sólidos de 2,5\% em 2,5\%, até cerca de $20 \%$ de material particulado. Nos ensaios com adição de finos, estes foram adicionados lentamente, acompanhados por um período de agitação de um minuto. A solução de defloculante utilizada era composta por $60 \%$ em peso de silicato de sódio e $40 \%$ de água. Com base na adição em gotas, calculou-se a porcentagem em peso de defloculante utilizada para $100 \mathrm{~g}$ de massa seca. A suspensão, para os testes, foi preparada utilizando dados decorrentes dos ensaios reológicos. Foram umificadas, ou granuladas (adição de 10\% em peso de água para melhorar o manuseio industrial do pó), duas formulações. A formulação 1 (padrão) consistiu na massa industrial, granulada com água. A formulação 2 (padrão+finos) consistiu na massa industrial granulada por aspersão de barbotina (nome dado industrialmente para a suspensão formada por argila e água), composta por água e $3 \%$ de finos. Em escala de laboratório, a aspersão foi efetuada utilizando-se um borrifador comum. As formulações foram, então, estocadas por 24 horas para homogeneização de umidade. Foi obtida a curva de compactação, com a finalidade de se determinar a pressão de prensagem que garantisse a obtenção de corpos-de-prova com massa específica equivalente à utilizada pelas empresas da região $\left(1,92 \mathrm{~g} / \mathrm{cm}^{3}\right)$. Prensaram-se corpos-deprova das formulações 1 e 2 , respectivamente com $325 \mathrm{kgf} / \mathrm{cm}^{2}$ e $375 \mathrm{kgf} / \mathrm{cm}^{2}$, de dimensões $7 \mathrm{~cm} \mathrm{x} 1 \mathrm{~cm}$, em prensa hidráulica de marca Luxor. Os corpos-deprova foram secos em estufa elétrica até peso constante. Foram realizados o ensaio de densidade aparente a seco (razão entre massa e volume da peça) e o módulo de ruptura a flexão a seco, em tensômetro Gabrielli. Quatro queimas foram realizadas, em forno tipo Mufla de laboratório, com taxa de aquecimento de $7^{\circ} \mathrm{C} / \mathrm{min}$ e patamar de 30 minutos, nas seguintes temperaturas: $1045^{\circ} \mathrm{C}, 1060^{\circ} \mathrm{C}$, $1075^{\circ} \mathrm{Ce} 1090^{\circ} \mathrm{C}$. Com os corpos-de-pro- 
Carolina Del Roveri et al.

va queimados, realizaram-se ensaios de absorção de água, segundo as normas ABNT NBR 13818 e retração linear de queima, calculada em função do comprimento dos corpos-de-prova antes e depois da queima, construindo, assim, a curva de gresificação das formulações. Além disso, realizou-se o ensaio de módulo de ruptura a flexão pós queima dos corpos-de-prova.

\section{Resultados e discussões}

Pelas análises químicas (Tabela 1) pôde-se observar que a massa-padrão e a fração fina apresentam composições químicas quase idênticas. Na difração de raios $\mathrm{X}$, verifica-se que os minerais encontrados nas duas amostras, são, praticamente, os mesmos (illita, quartzo, hematita, clorita, montmorillonita e caulinita). Estudos microscópicos da fração fina e da massa-padrão realizados pelo Grupo de Pesquisa "Qualidade em Cerâmica”, em congruência com os dados químicos e mineralógicos obtidos por raios $\mathrm{X}$, mostram que a mineralogia essencial é constituída por illita, albita, quartzo e quantidades menores, normalmente inferiores a $5 \%$, de hematita, clorita, micas, montmorillonita, caulinita e clastos de minerais pesados (Zanardo et al., 2004). Também mostram que os filossilicatos apresentam granulação média entre 5 e $10 \mu \mathrm{m}$, enquanto que os minerais granulares detríticos e autígenos apresentam granulação média ao redor de $50 \mu \mathrm{m}$, sendo que os grãos maiores, raramente, ultrapassam $120 \mu \mathrm{m}$, com a fração granulométrica superior a $62 \mu \mathrm{m}$ constituindo menos de $15 \%$ do volume. Esse tipo de descrição, comumente utilizada para rochas, foi utilizado pelo fato de a fração fina e de a massa-padrão serem produ- tos de moagem do mesmo material, argilitos e siltitos provenientes da mesma Formação geológica (Formação Corumbataí).

A distribuição do tamanho de partículas da massa e da fração fina é exposta na Figura 1.

Embora tenha sido observada a presença de minerais, como hematita e outros, foi utilizado o sedígrafo, para análise granulométrica, pois os percentuais desses minerais são muito baixos.

Pode-se observar que o volume de partículas, na fração inferior a $100 \mu \mathrm{m}$, apresentada pela fração fina ,é ligeiramente maior que a da fração fina da massa. Nas análises via sedígrafo, não foi observada diferenciação mineralógica significativa quanto à granulometria, uma vez que o ensaio é realizado com o material peneirado, abaixo de $100 \mu \mathrm{m}$. Assim, a fração da massa-padrão analisada se mostrou-se análoga à fração fina, em função da metodologia de ensaio e da natureza textural da matéria-prima e do tipo de moagem (moinho de martelo via seca), que resulta no predomínio de grãos poliminerálicos (a matéria-prima da Formação Corumbataí é formada por diversos minerais, que, por vezes, formam grânulos). A diferença entre o material retido no filtro de manga e a massa reside na quase ausência de grãos maiores que 100 $\mu \mathrm{m}$ no primeiro, fração esta que constitui cerca de $9 \%$ em peso da massa. Nas Figuras 2 e 3 , é apresentada a caracterização reológica do material retido no filtro de manga. Pode-se observar que, utilizando massa específica de $1,50 \mathrm{~g} / \mathrm{cm}^{3}$, a proporção de defloculante necessária seria de $0,16 \%$ em peso. Realizando o ensaio de conteúdo crítico de sólidos (Figura 3), verifica-se que pode-se chegar à concentração de sólidos em peso de $66 \%$, o que acarreta, porém, uma ele-

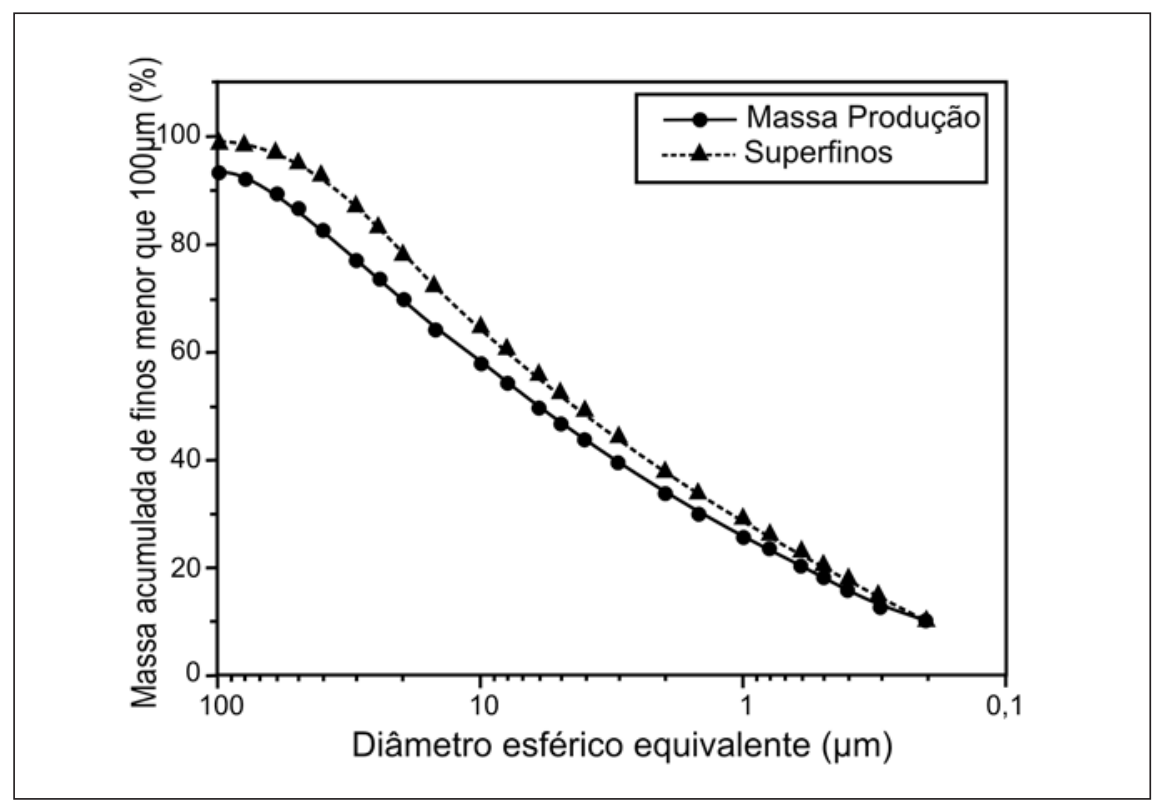

Figura 1 - Distribuição do tamanho de partículas das amostras (a amostra superfinos equivale à fração fina retida nos filtros de manga).

Tabela 1 - Resultado das análises químicas por fluorescência de raios $X$ (\% peso).

\begin{tabular}{c|c|c|c|c|c|c|c|c|c|c|c|c}
\hline Amostra & $\mathrm{SiO}_{2}$ & $\mathrm{TiO}_{2}$ & $\mathrm{Al}_{2} \mathbf{O}_{3}$ & $\mathrm{Fe}_{\mathbf{2}} \mathbf{O}_{3}$ & $\mathbf{M n O}$ & $\mathbf{M g O}$ & $\mathbf{C a O}$ & $\mathrm{Na}_{\mathbf{2}} \mathbf{O}$ & $\mathbf{K}_{\mathbf{2}} \mathbf{O}$ & $\mathbf{P}_{\mathbf{2}} \mathbf{O}_{\mathbf{5}}$ & P.F. & Total \\
\hline Massa & 66,45 & 0,65 & 15,42 & 5,59 & 0,08 & 1,64 & 0,38 & 0,93 & 3,10 & 0,10 & 5,90 & 100,24 \\
\hline Finos & 66,58 & 0,65 & 15,28 & 5,51 & 0,09 & 1,67 & 0,40 & 0,92 & 3,10 & 0,10 & 5,90 & 100,21 \\
\hline
\end{tabular}


vação na viscosidade da suspensão. Ao realizar o teste com massa específica de $1,25 \mathrm{~g} / \mathrm{cm}^{3}$, adequada para o consumo dos finos, por permitir o processo de aspersão, constatou-se que não havia necessidade do uso de defloculante, pois não havia modificação no comportamento reológico (viscosidade constante de $100 \mathrm{cP}$ e suspensão dispersa). Caso fosse utilizado defloculante, poderiam ser obtidas suspensões com concentrações de sólidos de até $62,8 \%$, para a mesma quantidade de silicato de sódio $(0,16 \%)$. Esse uso, porém, fica descartado, pois essa prática acarretaria obstrução do bico granulador nas empresas. Obtida a cur- va de compactação (Figura 4), observouse que a formulação 2 necessitou de maior pressão de compactação para que se obtivesse a mesma densidade. Isso se deve ao fato de que partículas finas acarretam maior retenção de ar entre os grumos, dificultando a compactação. Porém a diferença de pressão utilizada nas duas massas, para os padrões fabris, não é relevante.

Ainda utilizando a variação de pressão de prensagem, realizou-se o ensaio de módulo de ruptura a flexão a seco (Figura 5). Observou-se que a formulação composta por massa-padrão mais fração fina apresentou resistência mecânica sutilmente inferior à obtida pela massa- padrão. A fração fina modificou as características referentes à compactação da massa diretamente ligada à resistência mecânica. Porém esse gradiente não é significativo, pois os valores de resistência mecânica a seco se encontram na faixa ideal de trabalho (acima de $75 \mathrm{kgf} / \mathrm{cm}^{2}$ ), segundo CCB (2005).

A curva de gresificação das formulações é mostrada na Figura 6. Observou-se que, para as duas, houve decréscimo na absorção de água e acréscimo na retração linear de queima, com o aumento de temperatura. Isso ocorre porque, com o aumento da temperatura, as fases fluidas e líquidas são progressivamente liberadas da estrutura cristalina

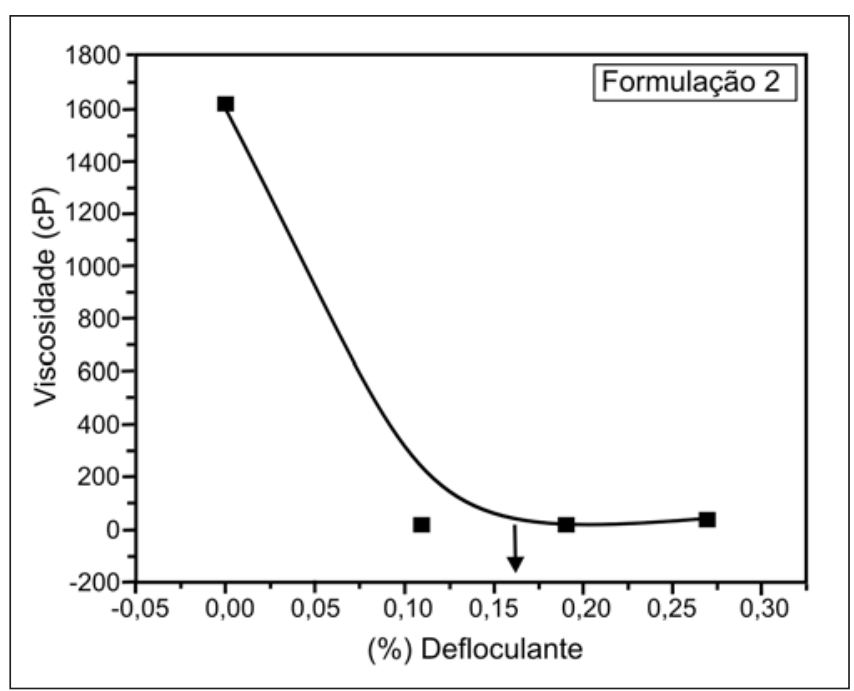

Figura 2 - Consumo de defloculante da formulação 2 (Padrão + Finos).

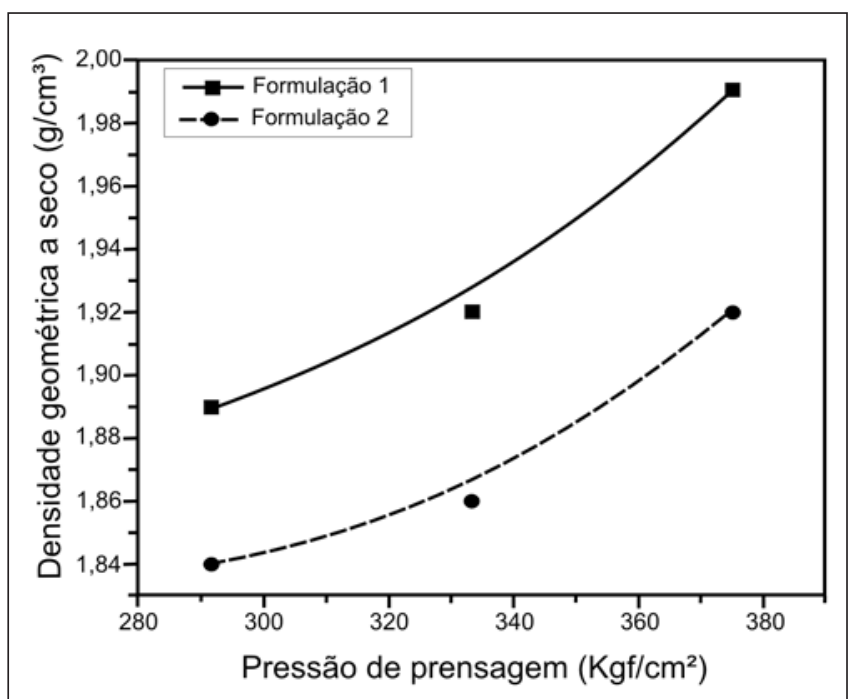

Figura 4 - Curva de compactação das formulações.

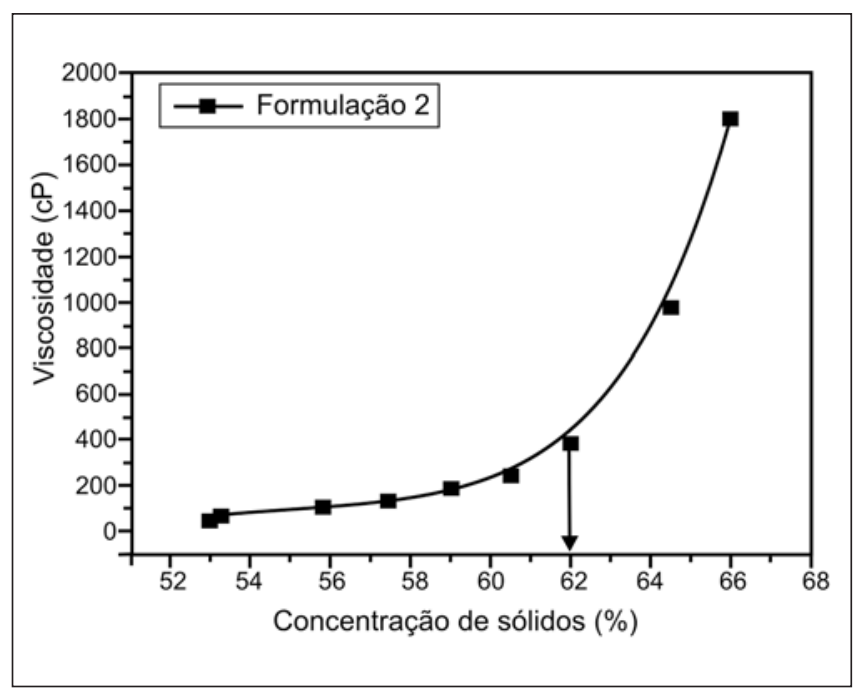

Figura 3 - Conteúdo crítico de sólidos da formulação 2.

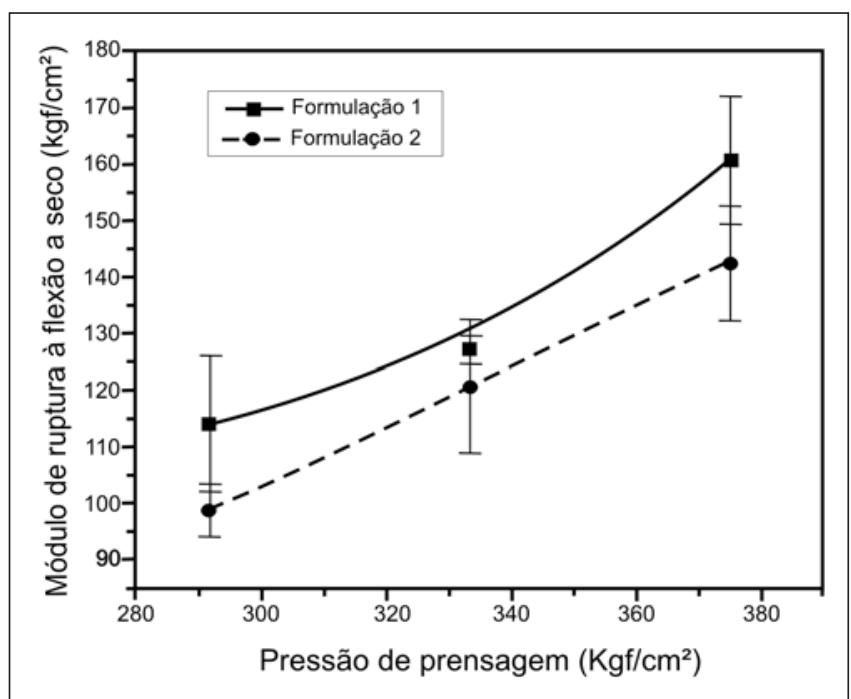

Figura 5 - Módulo de ruptura a flexão a seco das formulações.

382 REM: R. Esc. Minas, Ouro Preto, 59(4): 379-383, out. dez. 2006 


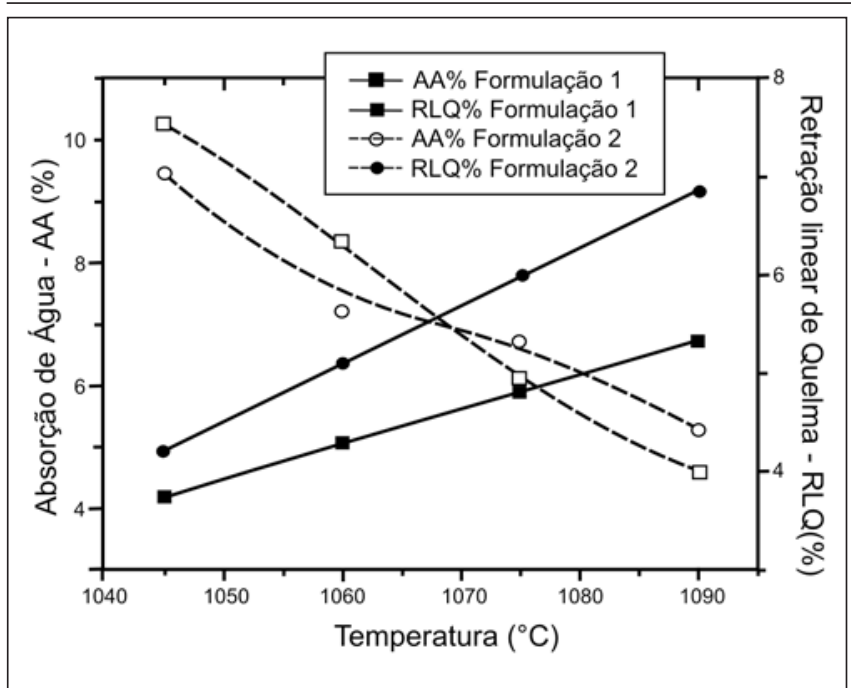

Figura 6 - Curva de gresificação das formulações, onde há a evolução da queima, mostrada pela absorção de água e retração linear de queima (duplo eixo $Y$ ) em função do aumento de temperatura (eixo X).

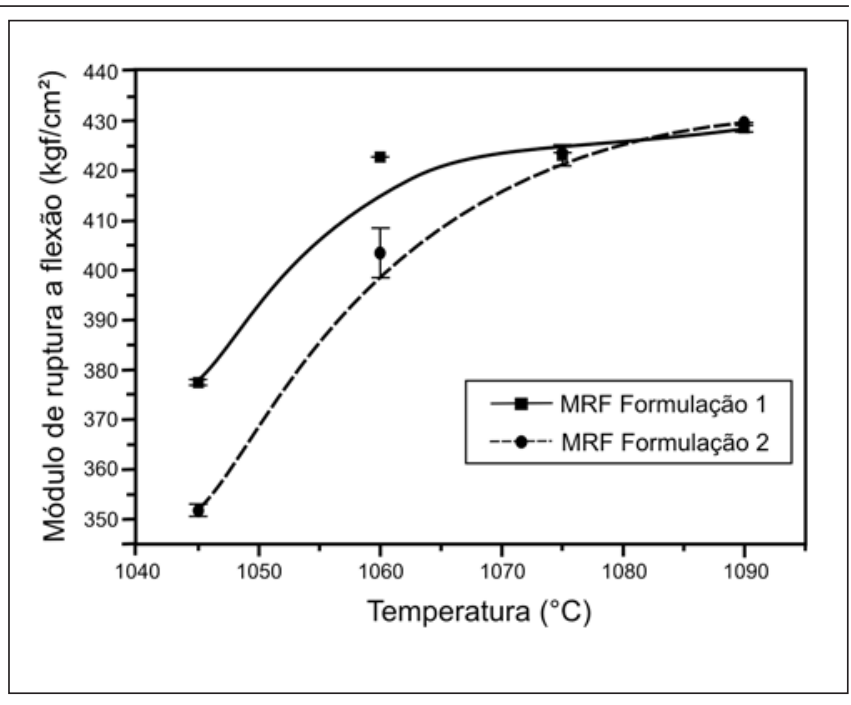

Figura 7 - Módulo de ruptura a flexão pós-queima dos corpos de prova. dos argilominerais, percolam os poros e, por força de capilaridade, os preenchem. Pôde-se observar que as duas formulações apresentaram valores de absorção de água equivalentes, pela mesma natureza físico-química da massa e da fração fina, porém a massa-padrão apresenta absorção maior até $1075^{\circ} \mathrm{C}$ e pouco menor em temperaturas superiores, aspecto resultante das diferenças de compactação. A diferença mais significativa refere-se à retração linear de queima, menor na massa-padrão, sendo que a diferença tende a aumentar com temperaturas crescentes de queima, em função da perda de massa com o aumento de temperatura. Constatou-se que a formulação composta pela massa-padrão + fração fina (Formulação 2) apresentou resistência mecânica pós-queima inferior à da massa padrão até determinada temperatura $\left(1075^{\circ} \mathrm{C}\right)$. Em temperaturas superiores, o módulo de ruptura das duas massas foi equivalente, indicando melhor sinterização das duas formulações (Figura 7).

A adição do pó em meio aquoso, formando a suspensão para ser empregada na umidificação (granulação) da massa cerâmica, ao invés de água pura como utilizado atualmente, deverá garantir, de forma homogênea (isto é, ocorrendo uma mistura efetiva entre os finos re- tidos nos filtros de manga e a massapadrão, sem a formação de grânulos ou distribuição irregular desses finos), o retorno dos finos à massa com as seguintes vantagens: aspecto ambiental (aproveitamento do pó fino do circuito, que ainda apresenta problemas de uso e de descarte), aspecto de prensagem e na queima (as partículas menores que ficam ao redor das maiores podem permitir um melhor desempenho e uma sinterização semelhante à massa-padrão.

\section{Conclusões}

Em vista dos resultados obtidos, pôde-se concluir que, de um modo geral, a reintegração dos finos retidos nos filtros de manga ao processo produtivo, através de aspersão de barbotina (aplicação de uma suspensão composta pelos finos retidos nos filtros de manga e água), é viável, uma vez que o produto gerado apresenta a qualidade final exigida por norma, contribuindo, assim, com a redução de custos industriais, além de sugerir novas alternativas para o passivo ambiental da indústria de revestimentos cerâmicos.

Novos estudos estão sendo realizados, procurando maximizar os resultados obtidos, buscando o cálculo de quanto material fino pode ser consumido e em que tal etapa do processo de fabricação isto ocorreria.

\section{Referências bibliográficas}

CCB - CENTRO CERÂMICO DO BRASIL. Como escolher e aplicar placas cerâmicas. CCB. São Paulo, 20 p. 2005.

MASSON,M.R. Caracterização de jazidas visando à garantia de qualidade de matérias-primas para a indústria cerâmica de revestimentos. Rio Claro: UNESP, 2001. 154p.

NASSETTI, G. Preparazione a secco degli impasti ceramici-dry grinding ceramic floor and wall tile mixes. Ceramica Acta, n. 5 - 6, p. 5-9, 1996.

ROVERI, C. D., ZANARDO, A. Estudo do comportamento reológico de argilas provenientes da Formação Corumbataí (região de Rio Claro/SP) - Resultados preliminares. In: SIMPÓSIO DE GEOLOGIA DO SUDESTE, 8. São Pedro, 2003. p. 188.

ZANARDO, A., ROVERI, C.D., MORENO, M.M.T., MASSON, M.R., BERNARDES, E.S. Petrografia da Formação Corumbataí na Região de Rio Claro - SP. In: CONGRESSO BRASILEIRO DE GEOLOGIA, 42, 2004, Araxá. Anais... v. 1, p. versão digital. 2004.

Artigo recebido em 02/01/2006 e aprovado em 31/08/2006. 